\title{
EGFR NM_005228.3:C.2319_2320insCAC
}

National Cancer Institute

\section{Source}

National Cancer Institute. EGFR NM 005228.3:C.2319 2320insCAC. NCI Thesaurus. Code C98689.

An insertion of three nucleotides, cytosine-adenine-cytosine, between position 2319 and 2320 of the coding sequence of the EGFR gene. 